JHR

36,6

1040

Received 17 January 2021

Revised 2 March 2021 18 April 2021

Accepted 26 May 2021

\section{Effect of an online psychological support group on patients with COVID-19 in a Thai field hospital: a real world study}

\author{
Tiraya Lerthattasilp, Lampu Kosulwit, Muthita Phanasathit, \\ Winitra Nuallaong, Pairath Tapanadechopone and \\ Chommakorn Thanetnit \\ Department of Psychiatry, Thammasat University, Bangkok, Thailand, and \\ Thammanard Charernboon \\ Department of Clinical Epidemiology, Thammasat University, Bangkok, Thailand
}

\begin{abstract}
Purpose - The purpose of this study is to evaluate the effectiveness of an online psychological support group on patients with coronavirus disease 2019 (COVID-19) in a Thai field hospital.

Design/methodology/approach - A prospective controlled trial was conducted at a Thai field hospital and included patients with confirmed COVID-19 who were over the age of 18 and able to use an online communication application. Patients were free to decide whether to participate in the online group. The group provided a space for participants to communicate with each other and a mental health service team. The everyday activities were designed to enable group support via texting or livestreaming through the LINE application. Psychoeducation via video clips or articles regarding stress management were provided. Outcomes were measured by an online self-reported questionnaire based on the twenty-one-item Depression, Anxiety and Stress Scale (DASS-21) on the first and fourteenth day of admission to the field hospital.

Findings - Forty-six patients participated in this study. Forty participants completed the secondary assessment, with 21 in the intervention group and 19 in the control group. From multilevel mixed-effects regression analysis, adjusted for gender, age and education, participation in the intervention group significantly decreased total DASS scores and anxiety subdomain scores compared to those in the control group $(p=0.038$ and 0.008$)$.

Originality/value - The online psychological support group offered benefits for patients with COVID-19 who were isolated in the field hospital. It could be an effective alternative measure to distribute psychological care during a pandemic situation. However, a small sample size was a limitation of this study.

Keywords COVID-19, Telemedicine, Online support group, Psychological impact, Psychological intervention Paper type Short report

\section{Introduction}

The novel coronavirus disease 2019 (COVID-19) was first designated as a global pandemic during the first trimester of 2020. Besides the impact of COVID-19 on physical health, studies

(C) Tiraya Lerthattasilp, Lampu Kosulwit, Muthita Phanasathit, Winitra Nuallaong, Pairath Tapanadechopone, Chommakorn Thanetnit and Thammanard Charernboon. Published in Journal of Health Research. Published by Emerald Publishing Limited. This article is published under the Creative Commons Attribution (CC BY 4.0) licence. Anyone may reproduce, distribute, translate and create derivative works of this article (for both commercial and non-commercial purposes), subject to full attribution to the original publication and authors. The full terms of this licence may be seen at http:// creativecommons.org/licences/by/4.0/legalcode

The authors would like to thank Thammasat Hospital's mental healthcare team, Dr. Natima Tiyao, Mr.Yingyod Whangprayoat and Assoc. Prof. Wanida Paoin for contributing to the mental healthcare of the patients at Thammasat University Field Hospital.
\end{abstract}

Funding: No funding was received for this study. 
report various mental health issues among patients, in particular depression, anxiety and stress [1-3]. Although the virus itself could give rise to a range of neuropsychiatric conditions [4], patients with COVID-19 can also be psychologically worsened by isolation, lack of knowledge of the disease and stigmatisation $[5,6]$.

Numerous articles highlight the importance of online psychological intervention, and various models have been discussed, including developing a qualified specialist team to address patients with emotional distress $[7,8]$ in addition to developing online materials for mental health education and online counselling $[9,10]$. Moreover, a study in China indicated the efficacy of internet-based self-help intervention in reducing depression and anxiety among patients affected by COVID-19 [11].

Thammasat University Field Hospital was the first field hospital in Thailand and operated between 26 March and 16 May 2020. Patients were referred to the field hospital from affiliated hospitals after their physical symptoms had improved and were stable. The purpose of the field hospital was to isolate patients until they were polymerase chain reaction (PCR) negative for COVID-19. Since these patients were separated in a single room for a long time, they were expected to present high rates of psychological distress. We found that the depression, anxiety and stress symptoms in patients at this field hospital were $22.5 \%, 30 \%$ and $20 \%$, respectively [12]. During the early phase of the COVID-19 pandemic in Thailand, although there were psychological assistance hotlines and online mental health education offered from the Department of Mental Health, there was no mental health service designed for patients affected by COVID-19 who were in quarantine [13].

The field hospital's mental healthcare team therefore designed and offered an online group activity to offer psychological support to these patients. The aim of this study was to examine the effectiveness of the online group support at reducing psychological distress among patients with COVID-19 at the Thammasat University Field Hospital.

\section{Methods}

\section{Participants and setting}

The present study was a real world, two-week prospective controlled study conducted at Thammasat University Field Hospital. Since the field hospital was modified from a university dormitory, patients with severe medical or neuropsychiatric conditions were not accepted to the field hospital. Each patient at the field hospital was provided with an individual room with a bathroom where they performed routine daily activities in isolation. Patients were unable to leave the room and the medical care team contacted them each day by phone. Free Wi-Fi was equipped in every room and patients could lend a mobile phone if they did not have their own. All patients were encouraged to contact their family and friends and could access public psychological assistance hotlines if they needed help.

The inclusion criteria of the study included being over the age of 18 , able to respond to the online questionnaire and able to use an online communication application. On the first day of admission to the field hospital, all patients were informed about the optional psychological care offered by the field hospital and asked whether they would like to participate in an online group activity via the LINE application. Other than using the LINE application to process the group activity, patients' personal data will be protected in another database. Patients received the same standard of medical care irrespective of whether they decided to join the group.

The study was approved by the Human Research Ethics Committee of Thammasat University (No. MTU-EC-PS-0-076/63). 
JHR

36,6

1042

\section{Intervention}

Patients who agreed to participate in the group activity were added to a chat room on the LINE online communication application, a commonly used social messaging application in Thailand. The group consisted of a psychiatrist, a psychologist, an occupational therapist, a family physician and a contemplative learning facilitator who took turn conducting activities. Activities included psychoeducation or group support via texting, video clip or LINE group call. The aims of the support group were to provide a space for participants to communicate with each other and with the mental health service team, to send messages to ensure they knew they were not alone and to reduce social stigma. Psychoeducation was provided by a video clip or an article each day which related to what to do during quarantine and stress management techniques such as breathing exercises, progressive muscle relaxation, meditation and exercise sessions that they perform within their rooms. Three times per week, a closed online video call group was conducted which included questions and answers about COVID-19 in addition to self-development sessions through activities, such as drawing and watching movies and contemplation. Participants were free to participate in any activities depending on their interests.

\section{Measurements}

Sociodemographic and mental health status information were collected by online selfreported questionnaires. Sociodemographic information included gender, age, educational level and the frequency of attending to activities (adherence). Mental health status was measured on the first and fourteenth day after admission by an online Thai version of the twenty-one-item Depression, Anxiety and Stress Scale (DASS-21). The DASS-21 is a selfreporting questionnaire to screen for mental health problems. Each of the three DASS-21 domains contains seven items, and the depression, anxiety and stress domains are calculated by summing relevant item scores and are divided into normal, mild-moderate, severe and extremely severe levels. The internal consistency for depression was 0.86 , anxiety was 0.81 and stress was 0.7 . The depression part of the DASS-21 indicated convergent validity with the Beck Depression Inventory $(r=0.53)$. The anxiety part had convergent validity with the Beck Anxiety Inventory $(r=0.51)[14,15]$. Patients whose score were moderate, high and extremely high on the DASS would receive individual online counselling by psychologists or psychiatrists.

\section{Statistical analysis}

Only participants with completed data were analysed. Data were analysed using STATA version 14. Descriptive statistics were used for the sociodemographic data. The exact test and independent t-test were employed to compare the difference between the intervention and the control groups. The mean differences of the total DASS scores between the intervention and control groups were compared using the independent t-test and multilevel mixed-effects regression analysis, adjusted for gender, age and education. A $p$-value $<0.05$ was considered to be statistically significant.

\section{Results}

Figure 1 depicts the enrolment and allocation of study participants. A total of 46 patients participated in the study. Six patients did not complete the secondary assessment, leaving 21 participants in the intervention group and 19 in the control group for data analysis. Table 1 presents the characteristics of both groups. The intervention group had a higher female-tomale ratio, a higher mean age and a smaller proportion of university graduates than the control group. The number of participants with depression, anxiety and stress at the baseline of the intervention group were higher than the control group. Except the number of 


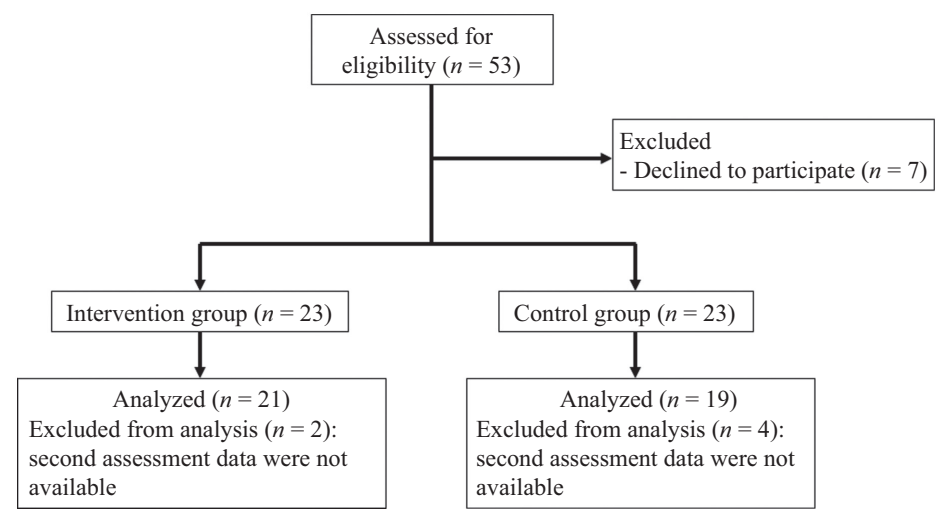

Online
psychological
support group

1043

Figure 1.

The enrolment and allocation of study participants

\begin{tabular}{|c|c|c|c|c|}
\hline & Intervention $(n=21)$ & Control $(n=19)$ & $p$-value & \\
\hline Gender: female & $16(76.2 \%)$ & $10(52.6 \%)$ & 0.186 & \\
\hline Age (years): mean (SD) [range $20-55$ years] & $31.7(10.4)$ & $26.8(6.1)$ & 0.082 & \\
\hline \multicolumn{5}{|l|}{ Education } \\
\hline (1) Primary school & $2(10 \%)$ & $0(0 \%)$ & 0.488 & \\
\hline (2) High school & $4(20 \%)$ & $6(31.6 \%)$ & & \\
\hline (3) University & $14(70 \%)$ & $13(68.4 \%)$ & & \\
\hline $\begin{array}{l}\text { Number of participants who received individual } \\
\text { counselling }\end{array}$ & $4(21.1 \%)$ & $5(27.8 \%)$ & 0.714 & \\
\hline \multicolumn{5}{|l|}{ Adherence to intervention } \\
\hline (1) None & 0 & $19(100 \%)$ & - & \\
\hline (2) Partial & $8(38.1 \%)$ & - & & \\
\hline (3) Full & $13(61.9 \%)$ & - & & \\
\hline Depression at baseline & $5(23.8 \%)$ & $1(5.3 \%)$ & 0.186 & \\
\hline Anxiety at baseline & $11(52.4 \%)$ & $1(5.3 \%)$ & 0.002 & \\
\hline Stress at baseline & $5(23.8 \%)$ & $1(5.3 \%)$ & 0.186 & Characteristics of the \\
\hline \multicolumn{5}{|c|}{ Note(s): Depression ( $>4$ points); anxiety ( $>3$ points); stress ( $>7$ points) } \\
\hline
\end{tabular}

participants with anxiety, the characteristic of both groups, did not differ statistically. None of the participants received psychiatric medications, for example, anxiolytic drugs.

From univariable analyses, the intervention group had significantly decreased total DASS scores (mean difference -5.1 vs $-1.8, p=0.043$ ) and anxiety subdomain scores $(-2.2$ vs -0.7 , $p=0.007$ ) than those assigned to the control group. After performing multilevel mixed-effects regression analysis, adjusted for gender, age and education, the intervention group still had a significant reduction in total DASS scores $(p=0.038)$ and the anxiety subdomain $(p=0.019)$ (Table 2 and Figure 2). Gender, age and education did not associate with the total DASS scores, depression subdomain, anxiety subdomain and stress subdomain.

\section{Discussion}

Thammasat University Field Hospital was the first field hospital in Thailand during the COVID-19 outbreak. The present study examined the effectiveness of an online psychological intervention to reduce psychological symptoms experienced by patients with COVID-19 during isolation in this field hospital. This study employed a real world, prospective and 


\section{JHR 36,6}

1044

Figure 2.

Difference of the total DASS score based on the baseline and second assessment between the intervention and control groups

\begin{tabular}{lcccccc}
\hline & Baseline & $\begin{array}{c}\text { Second } \\
\text { assessment }\end{array}$ & $\begin{array}{c}\text { Mean } \\
\text { difference }\end{array}$ & $\begin{array}{c}p \text {-value } \\
\text { (unadjusted) }\end{array}$ & $\begin{array}{c}p \text {-value } \\
\text { Cofficient* }\end{array}$ \\
\hline $\begin{array}{l}\text { Total DASS } \\
\text { Control }\end{array}$ & $5.5(5.0)$ & $3.7(4.6)$ & $-1.8(3.9)$ & 0.043 & - & 0.038 \\
Intervention & $12.9(13.4)$ & $7.7(10.9)$ & $-5.1(5.8)$ & & -3.36 & \\
$\begin{array}{l}\text { Depression } \\
\text { Control }\end{array}$ & $1.6(1.9)$ & $1.2(2.0)$ & $-0.4(1.3)$ & 0.064 & - & 0.056 \\
Intervention & $3.6(5.0)$ & $2.0(3.2)$ & $-1.6(2.5)$ & & -1.23 & \\
$\begin{array}{l}\text { Anxiety } \\
\text { Control }\end{array}$ & $1.5(2.0)$ & $0.8(1.4)$ & $-0.7(1.4)$ & 0.007 & - & 0.008 \\
Intervention & $4.4(4.8)$ & $2.2(4.0)$ & $-2.2(1.9)$ & & -1.42 & \\
$\begin{array}{l}\text { Stress } \\
\text { Control }\end{array}$ & $2.4(2.5)$ & $1.7(2.2)$ & $-0.7(2.4)$ & 0.488 & - & 0.409 \\
Intervention & $4.8(4.2)$ & $3.5(4.2)$ & $-1.3(2.9)$ & & -0.71 & \\
\hline
\end{tabular}

Note(s): *Multilevel mixed-effects regression analysis, adjusted for gender, age and education; Akaike information criterion (AIC): total DASS model - 512.5, depression model - 372.5, anxiety model -362.5 , stress model -393.1

controlled design. A standard randomised controlled trial was not possible due to the urgency of the situation and ethical issues during the pandemic.

This study found that an online group psychological intervention could reduce psychological impacts, especially anxiety symptoms. An explanation for the predominant reduction in anxiety symptoms was that the researchers provided a variety of relaxation techniques and question-answer sessions about COVID-19, that is, patients who were anxious and lacked knowledge about COVID-19 directly benefited from these interventions. As this study could have many sources of bias, we performed repeated measure analysis to alleviate the bias regarding an unequal DASS score at the baseline and adjusted age, gender and education. Although some participants received individual counselling as a co-intervention which might be other sources of bias, a number of participants with co-intervention were similar in both groups and none of the participants 
received anxiolytic drugs. However, six participants were excluded from our analysis because they did not complete the secondary assessment. The issue that the intervention group participants had higher baseline scores than the control group might be a bias for our outcome. This might be worth implying that patients with psychological distress sought after group support and benefited from it.

This finding is consistent with a previous study conducted in China which showed that patients with COVID-19 who received internet-based self-help psychological intervention [for example, breathing relaxation training, mindfulness (body scan)] exhibited significantly decreased depression and anxiety symptoms [11]. However, the way that the present study introduced psychological support was different and focused more on everyday psychological care through group support and psychoeducation, and less on a fixed schedule to train relaxation techniques.

The study results also show that internet-based interventions could be an effective measure for psychological care. This is relevant to a meta-analysis regarding guided internet-based vs. face-to-face cognitive behaviour therapy which indicated that guided internet-delivered cognitive behavioral therapy (ICBT) and face-to-face treatment produced equivalent overall effects in treatment of psychiatric disorders, for example, depressive symptom and social anxiety disorder [16].

\section{Clinical implication}

An online psychological support group is a simple method that could benefit patients suffering from a combination of COVID-19 and isolation. Such online support groups could be an effective alternative measure to distribute psychological care during a pandemic. In addition, this study could be used as a basis for further research on telepsychiatry for other psychiatric conditions as well.

However, it should be noted that although the DASS scores were reduced in the intervention group, the reduction points were subtle and might not be considered to be clinically important. Also, the reduction of anxiety during the second assessment might relate to the additional effect of the ending of self-isolation or quarantine on day 14 after admission.

\section{Limitations}

Since the study participants were free to join any activities whenever they wanted, it is not known how engaged they were with the activities or which activities were the most effective. Furthermore, only a small number of participants joined the study because the number of new COVID-19 cases in Thailand dropped significantly after one month of the study and the subsequent closure of the field hospital. This could limit the statistical power to detect real effects. The post-hoc power analyses of the total DASS score's mean difference was 0.567 and the anxiety part was 0.816 . Further randomised controlled studies with a larger sample size would clarify the efficacy of the intervention.

\section{Conclusion}

The present study found that an online psychological support group could reduce psychological distress, especially anxiety, among patients suffering from a combination of COVID-19 and isolation. Such online support groups could be an alternative measure to distribute psychological care during a pandemic. However, a small sample size was a limitation of this study.

\section{Conflict of Interest: None}

\section{References}

1. Özdin S, Özdin ŞB. Levels and predictors of anxiety, depression and health anxiety during COVID-19 pandemic in Turkish society: the importance of gender. Int J Soc Psychiatry. 2020; 66(5): 504-11. doi: 10.1177/0020764020927051. 
JHR

36,6

1046

2. Qi R, Chen W, Liu S, Thompson PM, Zhang LJ, Xia F, et al. Psychological morbidities and fatigue in patients with confirmed COVID-19 during disease outbreak: prevalence and associated biopsychosocial risk factors. medRxiv. doi: 10.1101/2020.05.08.20031666 [Preprint].

3. Guo Q, Zheng Y, Shi J, Wang J, Li G, Li C, et al. Immediate psychological distress in quarantined patients with COVID-19 and its association with peripheral inflammation: a mixed-method study. Brain Behav Immun. 2020; 88: 17-27. doi: 10.1016/j.bbi.2020.05.038.

4. Rogers JP, Chesney E, Oliver D, Pollak TA, McGuire P, Fusar-Poli P, et al. Psychiatric and neuropsychiatric presentations associated with severe coronavirus infections: a systematic review and meta-analysis with comparison to the COVID-19 pandemic. Lancet Psychiatry. 2020; 7(7): 611-27. doi: 10.1016/s2215-0366(20)30203-0.

5. Brooks SK, Webster RK, Smith LE, Woodland L, Wessely S, Greenberg N, et al. The psychological impact of quarantine and how to reduce it: rapid review of the evidence. Lancet. 2020; 395(10227): 912-20. doi: 10.1016/s0140-6736(20)30460-8.

6. Rajkumar RP. COVID-19 and mental health: a review of the existing literature. Asian J Psychiatr. 2020; 52: 102066. doi: 10.1016/j.ajp.2020.102066.

7. Zhou X, Snoswell CL, Harding LE, Bambling M, Edirippulige S, Bai X, et al. The role of telehealth in reducing the mental health burden from COVID-19. Telemed J E Health. 2020; 26(4): 377-9. doi: 10.1089/tmj.2020.0068.

8. Duan L, Zhu G. Psychological interventions for people affected by the COVID-19 epidemic. Lancet Psychiatry. 2020; 7(4): 300-2. doi: 10.1016/s2215-0366(20)30073-0.

9. Liu S, Yang L, Zhang C, Xiang YT, Liu Z, Hu S, et al. Online mental health services in China during the COVID-19 outbreak. Lancet Psychiatry. 2020; 7(4): e17-8. doi: 10.1016/s2215-0366(20) $30077-8$

10. Liu Y, Li J, Feng Y. Critical care response to a hospital outbreak of the 2019-nCoV infection in Shenzhen, China. Crit Care. 2020; 24(1): 56. doi: 10.1186/s13054-020-2786-x.

11. Wei N, Huang BC, Lu SJ, Hu JB, Zhou XY, Hu CC, et al. Efficacy of internet-based integrated intervention on depression and anxiety symptoms in patients with COVID-19. J Zhejiang Univ Sci B. 2020; 21(5): 400-4. doi: 10.1631/jzus.B2010013.

12. Lerthattasilp T, Kosulwit L, Phanasathit M, Nuallaong W, Tapanadechopone P, Thanetnit C, et al. Psychological impacts on patients with COVID-19 in a Thai field hospital. Arch Clin Psychiatry (São Paulo). 2020; 47(6): 215-7. doi: 10.15761/0101-60830000000265.

13. Thailand, Ministry of Public Health, Department of Mental Health. Covid-19 and mental health. [updated 2021; cited 2021 Apr 16]. Available from: https://www.dmh.go.th/covid19.

14. Lovibond SH, Lovibond PF. Manual for the depression anxiety stress scales. Sydney: Psychology Foundation; 1996.

15. Oei TP, Sawang S, Goh YW, Mukhtar F. Using the depression anxiety stress scale 21 (DASS-21) across cultures. Int J Psychol. 2013; 48(6): 1018-29. doi: 10.1080/00207594.2012.755535.

16. Andersson G, Cuijpers P, Carlbring P, Riper H, Hedman E. Guided Internet-based vs. face-to-face cognitive behavior therapy for psychiatric and somatic disorders: a systematic review and metaanalysis. World Psychiatry. 2014; 13(3): 288-95. doi: 10.1002/wps.20151.

\section{Corresponding author}

Thammanard Charernboon can be contacted at: dr.thammanard@gmail.com

For instructions on how to order reprints of this article, please visit our website:

www.emeraldgrouppublishing.com/licensing/reprints.htm

Or contact us for further details: permissions@emeraldinsight.com 